\title{
Help-seeking behaviors for female sexual dysfunction: a cross sectional study from Iran Mariam Vahdaninia ${ }^{1}$, Ali Montazeri ${ }^{1}$ and Azita Goshtasebi ${ }^{* 1,2}$
}

\author{
Address: ${ }^{1}$ Iranian Institute for Health Sciences Research (IHSR), ACECR, Tehran, Iran and ${ }^{2}$ Tarbiat Modarres University, Tehran/Iran \\ Email: Mariam Vahdaninia - vahdaninia@acecr.ac.ir; Ali Montazeri - montazeri@acecr.ac.ir; Azita Goshtasebi* - agoshtasebi@ihsr.ac.ir \\ * Corresponding author
}

Published: 27 February 2009

BMC Women's Health 2009, 9:3 doi:10.1 186/1472-6874-9-3

This article is available from: http://www.biomedcentral.com//472-6874/9/3

(C) 2009 Vahdaninia et al; licensee BioMed Central Ltd.

This is an Open Access article distributed under the terms of the Creative Commons Attribution License (http://creativecommons.org/licenses/by/2.0), which permits unrestricted use, distribution, and reproduction in any medium, provided the original work is properly cited.
Received: 15 October 2008

Accepted: 27 February 2009

\begin{abstract}
Background: Female sexual dysfunctions (FSD) are prevalent multifactor problems that in general remain misdiagnosed in primary health care. This population-based study investigated help-seeking behaviors among women with FSD in Iran.

Methods: This was a cross sectional study carried out in Kohgilouyeh-Boyer-Ahmad province in Iran. Using quota sampling all sexually active women aged I 5 and over registered in primary health care delivery centers were studied. Experience of sexual problems was assessed using an ad-hoc questionnaire (Female sexual dysfunction: help-seeking behaviors survey) containing 14 items. Trained female nurses interviewed all participants after a verbal informed consent. Data were analyzed in a descriptive manner.

Results: In all 1540 women were studied. Of these, 786 (5I\%) cases had experienced at least one of the FSD problems. Results showed that $35.8 \%$ of women with FSD had sought no professional help and the most reasons for not seeking help were identified as: 'time constraints' and believing that it 'did not occur to me' (39.I and $28.5 \%$ respectively). Sixty one percent of women who sought help for FSD reported that 'doctor gave me a definite diagnosis' and 'a definite treatment plan was given' in $57 \%$ of cases.
\end{abstract}

Conclusion: The study findings indicated that FSD problems were prevalent and many women did not seek help for their problem. Finding 'time constraints' and believing that the problem 'did not occur to me' as the most cited reasons for not seeking help might facilitate to understand potential barriers that exist in recognition and treatment of the female sexual dysfunctions. Since FSD might have a negative impact on interpersonal relationships and women's quality of life, it seems that there is need to address the problem both at local and national primary health care services.

\section{Background}

Female sexual dysfunctions (FSD) are gender-related prevalent multifactor problems. Studies on epidemiologic aspects of these disorders are sparse. Also, inconsistent definitions of FSD, characteristics of different populations and sample size restrictions make difficult the compara- bility of FSD estimates in an international level [1]. A study on sexual problems among men and women aged $40-80$ years from 29 countries found that about half of all sexually active women had experienced at least one sexual problem [2]. However the study sample was not representative of each country's adult population. 
Studies have shown that FSD might cause a negative impact on interpersonal relationships and quality of life. It is argued that intimacy in sexual relationships and favor sexual function has an essential role in maintaining psychological satisfaction and good quality of life [3-6]. Similarly studies indicated that satisfaction with emotional and physical sexual relationships is predictive of subjective sexual well being in elderly [7]. In addition, sexual problems are considered as a vicious circle in infertility and reproductive disorders. Childlessness may be the result of a neglected sexual dysfunction that could be elucidated in medical consultation. Also stress due to infertility may interact with couples' or individuals' sexuality and result in arousal difficulties [8].

Evidence suggests that despite the high prevalence of FSD disorders these problems frequently go undetected in primary health care services $[9,10]$. Improvement of knowledge and skills in general practice as well as contextual changes are suggested solutions for better management of sexual dysfunctions [10]. Many people like to discuss their sexual problems with doctors during their routine visits [11], but the question remains whether the primary healthcare professionals are prepared to deal with such problems.

As part of a study on women's health, an investigation was carried out to assess FSD prevalence and help-seeking behaviors among sexually active women in KohgilouyehBoyer-Ahmad province, in Iran. The province is located in southwest of Iran and has 700,000 inhabitants. In general, the province is known as a deprived area but its primary healthcare system is very well organized and most people use the services for their health-related problems.

\section{Methods}

\section{Design and data collection}

This was a cross-sectional study carried out in year 2005 . A team of trained female nurses interviewed all participants after a verbal informed consent.

\section{Questionnaire}

The questionnaire was derived from the literature $[2,12]$. Two psychiatrists and a clinical psychologist assessed and confirmed its content validity. Then the questionnaire was pilot tested to examine if the questions were clear and acceptable. Considering cultural issues and that the survey was being conducted in a deprived area, some items were amended or reduced. The final questionnaire consisted of 14 items in three parts: demographic characteristics (3 items), experience of FSD ( 6 items), and 5 items on helpseeking behaviors [Additional file 1]. Sexual problems were defined as: desire disorder (DD), arousal disorder $(A D)$, lubrication disorder (LD), orgasmic disorder (OD), satisfaction disorder (SD) and pain disorder (PD). Experi- ence of any of the defined sexual problems was assessed by a single self-reported question during the last 3 months. The level or degree of the disorders was rated on a 4-point scale. For analysis response categories were combined to yield either "existence of the problems" or "lack of the disorder".

Help-seeking behavior among women with FSD was assessed by asking women: "Have you ever sought any help from healthcare services for your problem?" A list of services was provided and more than one service could be indicated. Subjects who had not sought professional consultation were asked about the reasons. Also they were asked, "If they are willing to have treatment now?" Finally, attitudes and beliefs towards the medical consultation in women who sought help for their problems also were assessed.

\section{The sample}

From a pilot study we estimated that for the main study there is need for a sample of 1500 sexually active women. The study population consisted of all sexually active married women aged 15 and over. Exclusion criteria were pregnancy, having chronic diseases and mental disorders. To select a representative sample of the population, a stratified multi stage area sampling was applied. Every woman registered in primary healthcare centers had the same probability to be sampled.

\section{Analysis}

Data were analyzed using SPSS 13 in a descriptive fashion and restricted to those who had FSD.

\section{Ethics}

The study was approved by the Iranian Academic Center for Education, Culture and Research (ACECR). All women gave their oral informed consent.

\section{Results}

In all 1540 women were studied. Of these, 786 (51.\%) women were found to experience FSD. The mean age of women with FSD was 33.2 years $(\mathrm{SD}=9.4 \%)$, and mostly were housewife $(86.4 \%)$. There were significant differences between educational and employment status of women with and without FSD indicating that those with FSD were less educated and more housewife. Table 1 shows the demographic characteristics of the study sample.

Age distribution of women with FSD and its items is shown in Table 2. Orgasmic disorder (OD) was found to be the most prevalent disorder among women (38.0\%) and lubrication disorder (LD) was the least reported one $(21.0 \%)$. In youngest age group ( $\leq 20$ years) the most observed FSD disorder was pain disorder (PD, 37\%) and 
Table I: Demographic characteristics of the study sample

\begin{tabular}{|c|c|c|c|c|}
\hline & Total sample & With FSD & Without FSD & $\mathbf{P *}$ \\
\hline & Number (\%) & Number (\%) & Number (\%) & \\
\hline Age (groups) & $(n=1540)$ & $(n=786)$ & $(n=754)$ & 0.4 \\
\hline$\leq 20$ & $90(5.8)$ & $54(6.9)$ & $36(4.8)$ & \\
\hline $21-30$ & $591(38.5)$ & $292(37.2)$ & $299(39.7)$ & \\
\hline $31-40$ & $552(35.8)$ & $278(35.3)$ & $274(36.3)$ & \\
\hline $4 I-50$ & $239(15.5)$ & $128(16.3)$ & III (14.7) & \\
\hline$\geq 5$ I & $68(4.4)$ & $34(4.3)$ & $34(4.5)$ & \\
\hline Mean (SD) & $33.2(9.4)$ & $33.2(9.4)$ & $33.2(9.3)$ & \\
\hline Educational Status & $(n=1470)$ & $(n=752)$ & $(n=718)$ & $<0.001$ \\
\hline Illiterate & $236(16.1)$ & $126(16.8)$ & $110(15.3)$ & \\
\hline Primary & $428(29.1)$ & $242(32.2)$ & $186(25.9)$ & \\
\hline Secondary & $27 \mid(18.4)$ & $132(17.6)$ & $139(19.4)$ & \\
\hline High school & $378(25.7)$ & $196(26.1)$ & $182(25.3)$ & \\
\hline University & $157(10.7)$ & $56(7.3)$ & $101(14.1)$ & \\
\hline Mean (SD) & $7.1(4.8)$ & $6.7(4.6)$ & $7.6(4.9)$ & \\
\hline Employment Status & $(n=1540)$ & $(n=786)$ & $(n=754)$ & 0.03 \\
\hline Housewife & $|30|(84.5)$ & $679(86.4)$ & $622(82.5)$ & \\
\hline Others & $239(15.5)$ & $107(13.6)$ & $132(17.5)$ & \\
\hline
\end{tabular}

$* \chi^{2}$ test

arousal disorder (DD) was the most prevalent disorder (61.8\%) among older age group ( $\geq 51$ years).

Table 3 presents the help-seeking behavior and reasons for not seeking help for FSD. In general 505 women (64.2\%) had sought professional consultation and 281 cases $(35.8 \%)$ had sought none. Most of the women had sought help from a gynecologist or a general practitioner (33.2 and $13.9 \%$ respectively). The most reported reasons for not seeking help were: 'I had time constraints' (39.1\%) and 'It did not occur to me' (28.5\%). Also, 'Being ashamed to speak about the problem' and 'doctor can't help me' were cited by $9.6 \%$ of women respectively. However, $56.9 \%$ of these cases had willing to have treatment for their disorder.
Attitudes and beliefs towards medical consultations in women who had sought help for FSD is shown in Table 4. Doctor had given genital examination in most of the cases (69.0\%). Based on the results $60.8 \%$ of women believed that their doctor gave them a definite diagnosis. Also $57.0 \%$ of subjects believed that "doctor gave them a definite treatment plan".

The relationships between demographic characteristics and help-seeking behavior for FSD women were examined. No significant associations were observed between women who sought and who did not seek help for their FSD problems regarding their age, education and employment. 
Table 2: Age distribution of FSD

\begin{tabular}{|c|c|c|c|c|c|c|}
\hline & $\leq 20(n=54)$ & $21-30(n=292)$ & $31-40(n=278)$ & $4 I-50(n=128)$ & $\geq 5 I(n=34)$ & All $(n=786)$ \\
\hline & Number (\%) & Number (\%) & Number (\%) & Number (\%) & Number (\%) & Number (\%) \\
\hline \multicolumn{7}{|l|}{ DD } \\
\hline No & $40(74.1)$ & $210(71.9)$ & $|7|(6 \mid .5)$ & $84(65.6)$ & $13(38.2)$ & $518(65.9)$ \\
\hline Yes & $14(25.9)$ & $82(28.1)$ & $107(38.5)$ & $44(34.4)$ & $21(61.8)$ & $268(34.1)$ \\
\hline \multicolumn{7}{|l|}{ AD } \\
\hline No & $43(79.6)$ & $200(68.5)$ & $179(64.4)$ & $82(64.1)$ & $21(61.8)$ & $525(66.8)$ \\
\hline Yes & II (20.4) & $92(31.5)$ & $99(35.6)$ & $46(35.9)$ & $13(38.2)$ & $26 \mid(33.2)$ \\
\hline \multicolumn{7}{|l|}{ LD } \\
\hline No & $47(87.0)$ & $234(80.1)$ & $211(75.9)$ & $103(80.5)$ & $26(76.5)$ & $621(79.0)$ \\
\hline Yes & $7(13.0)$ & $58(19.9)$ & $67(24.1)$ & $25(19.5)$ & $8(23.5)$ & $165(2 \mid .0)$ \\
\hline \multicolumn{7}{|c|}{$O D^{3}$} \\
\hline No & $36(66.7)$ & $179(61.3)$ & $17 \mid(6 \mid .5)$ & $80(62.5)$ & $21(61.8)$ & $487(62.0)$ \\
\hline Yes & $18(33.3)$ & $113(38.7)$ & $107(38.5)$ & $48(37.5)$ & $13(38.2)$ & $299(38.0)$ \\
\hline \multicolumn{7}{|l|}{ PD } \\
\hline No & $34(63.0)$ & $189(64.7)$ & $193(69.4)$ & 92 (71.9) & $28(82.4)$ & $536(68.2)$ \\
\hline Yes & $20(37.0)$ & $103(35.3)$ & $85(30.6)$ & $36(28.1)$ & $6(17.6)$ & $250(31.8)$ \\
\hline \multicolumn{7}{|l|}{ SD } \\
\hline No & $39(72.2)$ & $182(62.3)$ & $179(64.4)$ & 79 (6I.7) & $21(61.8)$ & $500(63.6)$ \\
\hline Yes & $15(27.8)$ & $110(37.7)$ & 99 (35.6) & $49(38.3)$ & $13(38.2)$ & $286(36.4)$ \\
\hline
\end{tabular}

DD: Desire Disorders, AD: Arousal Disorders, LD: Lubrication Disorders, OD: Orgasmic Disorders, PD: Pain Disorders, SD: Satisfaction Disorders

\section{Discussion}

This study provided data on FSD prevalence and its helpseeking behavior in sexually active women aged 15 years old and over in Kohgilouyeh-Boyer-Ahmad province/ Iran. In this study sexual problems that were experienced in the last 3 months were considered as "dysfunction". This allowed minimizing the false positive responses and obtaining more valid data on FSD. Also most of the women were interested in participating in the study and the overall response rate was $92 \%$.

Fifty one percent of the whole study population (786/ 1540) had experienced at least one of the sexual problems and the most observed dysfunction was "orgasmic disorder" (Table 2). High prevalence of sexual problems among women is reported in different populations $[5,11$ $16]$.

The results showed that $64.2 \%$ of women had attempted to seek medical consultation for their disorder. The Global Study on Sexual Attitudes and Behaviors (GSSAB) in 29 countries showed that although about half of all sexually active respondents had experienced at least one sexual problem, less than $18.8 \%$ of women had sought medical help for their sexual problems [2]. It is argued that seeking 
Table 3: Help-seeking patterns for FSD among women

\begin{tabular}{|c|c|c|}
\hline & Number & $\%$ \\
\hline \multicolumn{3}{|l|}{ Help-seeking for FSD $(n=786)$} \\
\hline None & 281 & 35.8 \\
\hline From gynecologist & 261 & 33.2 \\
\hline From general practitioner & 109 & 13.9 \\
\hline From psychiatrist & 11 & 1.4 \\
\hline From more than one health professionals & 124 & 15.7 \\
\hline \multicolumn{3}{|l|}{ Attitudes and beliefs for not seeking help for FSD $(n=281)$} \\
\hline I am ashamed to speak about it & 27 & 9.6 \\
\hline Doctor can not help me & 27 & 9.6 \\
\hline I had time constraints & 110 & 39.1 \\
\hline It did not occur to me & 80 & 28.5 \\
\hline I was not asked about my problem during my routine visit(s) & 5 & 1.8 \\
\hline Responding to more than one choices & 32 & 11.4 \\
\hline \multicolumn{3}{|l|}{ Are you willing to have treatment now? $(n=28 I)$} \\
\hline No & 62 & 22.1 \\
\hline Yes & 160 & 56.9 \\
\hline I am not sure & 59 & 21.0 \\
\hline
\end{tabular}

help for sexual problems reflects awareness of the availability of advice and treatment for these disorders [17].

In this study most women had referred to a gynecologist (33.2\%) and a general practitioner (13.9\%) While a small proportion of women with FSD (1.4\%) had sought help from a psychiatrist. In addition $15.4 \%$ of women had sought help from more than one health professionals (Table 3). The latter implies that women had been dissatisfied with their initial management and had sought further consultations from other health professionals. Moreover the observed diverse pattern of help-seeking for FSD is suggestive that there is not a definite diagnosis and treatment plan for FSD in primary health care services in Iran. The GSSAB has found that among women an attempt to seek medical help for sexual problems has been $18.8 \%$ and about $1-8 \%$ of seeking psychological help (psychiatrist, psychologist or marriage counselor) has been reported [2].

'Time constraints' and believing that the problem 'did not occur to me' were the most cited reasons for not consulting a doctor for FSD. Also, the belief that 'doctor cannot help me' was reported by $9.6 \%$ of women (Table 3 ). It seems these reasons indicate that women with FSD may not consider their problem serious. Similarly studies have found that not feeling on the severity of the sexual problems may deter individuals discussing their sexual difficulties $[18,19]$. In addition the idea that 'the sexual problem was a normal part of getting older/being comfortable the way I am' were commonly cited reasons by women in GSSAB study [2].

Other beliefs in respect of not seeking help were: 'Being ashamed to speak about the problem' and 'not being 
Table 4: Attitudes and beliefs towards the medical consultation in women who sought help for FSD

\begin{tabular}{|c|c|c|}
\hline & Agree & Disagree \\
\hline & Number (\%) & Number (\%) \\
\hline Doctor listened carefully to me $(n=485)$ & $396(81.6)$ & $89(18.4)$ \\
\hline Doctor gave me a genital examination $(n=47 I)$ & $325(69.0)$ & $146(31.0)$ \\
\hline Doctor ordered lab tests $(n=485)$ & $342(70.5)$ & $143(29.5)$ \\
\hline Doctor asked about my emotional and mental status $(n=470)$ & $231(49.0)$ & $239(51.0)$ \\
\hline Doctor enquired about the quality of my sex life $(n=463)$ & $241(52.0)$ & $222(48.0)$ \\
\hline Doctor gave me a definite diagnosis $(n=472)$ & $287(61.0)$ & $185(39.0)$ \\
\hline Doctor gave me a definite treatment plan $(n=477)$ & $272(57.0)$ & $205(43.0)$ \\
\hline
\end{tabular}

asked by the doctor during routine visits' (Table 3). Similar findings have indicated that doctors in Europe and other countries rarely ask patients about their sexual health during a routine consultation even though patients would appreciate this $[2,18,19]$. The reluctance to initiate a discussion about sexual health is a dual interaction between patients and doctors. This may be in part affected by patients' barriers such as embarrassment, lack of knowledge and indirect presentation of the disease [10]. On the other hand due to the lack of appropriate medical training on sexual problems, doctors encounter difficulties in the management and treatment of these disorders [20].

We found that $81.6 \%$ of women who sought medical consultation agreed that 'doctor listened carefully to them' while $48 . \%$ of cases disagreed with 'being asked by doctor about the quality of their sexual life' (Table 4). Also 61.\% and $57 . \%$ of these women agreed that 'doctor gave them a definite diagnosis and treatment plan', respectively. It seems that physicians often feel unqualified to treat patients with sexual dysfunctions and there is a need for more professional and patient education as well as relevant secondary care services $[10,21]$.

This study provided useful information and indicated the extent of the FSD problems in a deprived area. However, the study has its own limitations. Different domains of the female sexual dysfunctions were assessed only by one question while one might argue there is need to ask more questions for each disorder to elucidate the problem. In addition, since the study relied on women's subjective impression of the FSD treatment (Table 4), the study was limited in conveying the current management of the FSD in Iran.

\section{Conclusion}

The study findings indicated that FSD problems were prevalent and many women did not seek help for their problem. 'Time constraints' and believing that the problem 'did not occur to me' as the most cited reasons for not seeking help might facilitate to understand potential barriers that exist in recognition and treatment of the female sexual dysfunctions. Since FSD might have a negative impact on interpersonal relationships and women's quality of life, it seems that there is need to address the problem both at local and national primary health care services.

\section{Abbreviations}

FSD: Female Sexual Dysfunction; DD: Desire Disorders; AD: Arousal Disorders; OD: Orgasmic Disorders; PD: Pain Disorders; LD: Lubrication Disorders; SD: Satisfaction Disorders; GSSAB: Global Study on Sexual Attitudes and Behaviors.

\section{Competing interests}

The authors declare that they have no competing interests.

\section{Authors' contributions}

MV analyzed the data and wrote the paper. AM contributed to data analysis and editing the final draft. AG designed and carried out the study. All authors read and approved the final manuscript. 


\section{Additional material}

\section{Additional file 1}

Female sexual dysfunction: help-seeking behaviors survey. This is a short self-reported questionnaire assessing female sexual dysfunction and its help-seeking behaviors. It also asks about the reasons of not seeking help. Click here for file

[http://www.biomedcentral.com/content/supplementary/14726874-9-3-S1.doc]

\section{Acknowledgements}

Yasuj University of Medical Sciences/Iran supported the study. We wish to thank all the University staff that made this study possible.

\section{References}

I. Dunn KM, Kelvin J, Croft PR, Assendelft WJJ: Systematic review of sexual problems: epidemiology and methodology. I Sex Marital Ther 2002, 28:399-422.

2. Moreira ED, Brock G, Glasser DB, Nicolosi A, Laumann EO, Paik A Wang T, Gingell C: Help-seeking behavior for sexual problems: the Global Study of Sexual Attitudes and Behaviors. Int J Clin Pract 2005, 59:6-16.

3. Rosen RC: Prevalence and risk factors of sexual dysfunction in men and women. Curr Psychiatry Rep 2000, 2: 189-195.

4. Warnock J]: Female hypoactive sexual desire disorder: epidemiology, diagnosis and treatment. CNS Drugs 2002, I 6:745-753.

5. Hisasue S, Kumamoto $Y$, Sato $Y$, Masumori N, Horita H, Kato R, Kobayashi K, Hashimoto K, Yamashita N, Itoh N: Prevalence of female sexual dysfunction symptoms and its relationship to quality of life: a Japanese female cohort study. Urology 2005, 65:143-148.

6. Daker-White G, Donovan J: Sexual satisfaction, quality of life and the transaction of intimacy in hospital patients accounts of their (hetero) sexual relationships. Sociol Health IIIn 2002, 24:89-II3.

7. Laumann EO, Paik A, Glasser DB, Kang JH, Wang T, Levinson B, Moreira ED, Nicolosi A, Gingell C: A cross-national study of subjective sexual well-being among older women and men: findings from the global study on sexual attitudes and behaviors. Arch Sex Behav 2006, 35:145-161.

8. Read J: Sexual problems associated with infertility, pregnancy and ageing. BM/ 2004, 329:559-56I.

9. Laumann E, Paik A, Rosen R: Sexual dysfunction in the United States-prevalence and predictors. I Am Med Assoc 1999 28I:537-544.

10. Humphery S, Nazareth I: GPs' views on their management of sexual dysfunction. Fam Pract 200I, I 8:516-5I8.

I I. Nazareth I, Boynton P, King M: Problems with sexual function in people attending London general practitioners: cross sectional study. BMJ 2003, 327:423-429.

12. Rosen R, Brown C, Heiman J, Leiblum S, Meston C, Shabsigh R, Ferguson D, D'Agostino R Jr: The Female Sexual Function Index (FSFI): a multidimentional self-report instrument for the assessment of female sexual dysfunction. J Sex Marital Ther 2000, 26: $19 \mid-208$.

13. Abdo CHN, Oliviera WM, Moreira ED, Fittipaldi JAS: Prevalence of sexual dysfunctions and correlated conditions in a simple of Brazilian women-results of the Brazilian study on sexual behavior (BSSB). Int J Impot Res 2004, I 6: I60-166.

14. Moreira ED, Kim SCh, Gkasser D, Gingell C: Sexual activity, prevalence of sexual problems and associated help-seeking patterns in men and women aged 40-80-years in Korea: data from the Global Study of Sexual Attitudes and Behaviors (GSSAB). I Sex Med 2006, 3:20I-2II.

15. Safarinejad MR: Female sexual dysfunction in a populationbased study in Iran: prevalence and associated risk factors. Int J Impot Res 2006, I 8:382-395.
16. Oksuz E, Malhan S: Prevalence and risk factors for female sexual dysfunction in Turkish women. J Urol 2006, I 75:654-658.

17. Mercer $\mathrm{CH}$, Fenton KA, Johnson AM, Wellings K, Macdowall W, McManus S, Nanchahal K, Erens B: Sexual function problems and help seeking behavior in Britain: national probability sample survey. BMJ 2003, 327:426-427.

18. Moreira ED, Glasser DB, Nicolosi A, Duart FG, Gingell C: Sexual problems and help-seeking behaviour in adults in the United Kingdom and continental Europe. BJU 2008, I 01 : I005-I0I I.

19. Moniz G, Cruz FO: Prevalence of sexual problems and related help-seeking behaviors among mature adults in Brazil: data from the Global Study of Sexual Attitudes and Behaviors. Sao Paulo Med J 2005, 23:234-24I.

20. Whitmore J: Problems with sexual function: training in psychosocial medicine is available for doctors. BM] 2003 327: I 109- I I 10

21. Philips NA: Female sexual dysfunction: evaluation and treatment. Am Fam Physician 2000, 62: I27-I36.

\section{Pre-publication history}

The pre-publication history for this paper can be accessed here:

http://www.biomedcentral.com/1472-6874/9/3/prepub
Publish with Biomed Central and every scientist can read your work free of charge

"BioMed Central will be the most significant development for disseminating the results of biomedical research in our lifetime. "

Sir Paul Nurse, Cancer Research UK

Your research papers will be:

- available free of charge to the entire biomedical community

- peer reviewed and published immediately upon acceptance

- cited in PubMed and archived on PubMed Central

- yours - you keep the copyright
BioMedcentral 